\title{
Estudo morfológico da glândula pineal do cão
}

\section{Morphologic study of the pineal gland of the dog}

\author{
Lucas Alécio Gomes ${ }^{1 *}$; Irvênia Luiza de Santis Prada ${ }^{2}$; Eduardo Cunha Farias \\ Jakeline Paola Zanon ${ }^{4}$; Selwyn Arlington Headley ${ }^{5}$; Francisco Xavier Hernandez Blazquez ${ }^{6}$
}

\section{Resumo}

\begin{abstract}
Após a descoberta da melatonina por Lerner et al. (1958), novas pesquisas e perspectivas surgiram tornando a pineal uma estrutura mais estudada. Além disso, sabe-se que este hormônio está relacionado com o controle circadiano e outras funções comportamentais fisiológicas como o ciclo reprodutivo e termorregulação. Neste trabalho, foram utilizados 20 cães e estudamos a morfologia das glândulas, empregando uma análise macroscópica e microscópica. O formato das pineais variou de cônico a glossóide (em relação à língua humana); cor entre bege e marrom-acinzentado e apresentaram consistência gelatinosa. A largura e o comprimento das glândulas variaram respectivamente de 1,38 a 2,39 mm e de 1,53 a 2,96 mm. Quanto à microscopia, utilizamos coloração de eosina-hematoxilina (HE), e em todas as pineais observamos a presença dos seguintes componentes: cápsula; septos ou trabéculas pinealócitos; células da glia; grânulos de pigmentos, e não foram notadas concreções calcáreas.
\end{abstract}

Palavras-chave: Cão, pineal, pinealócitos, células da Glia, macroscopia, microscopia

\begin{abstract}
Following the discovery of the melatonin by Lerner et al. (1958), new research and perspectives were developed in order to improve the knowledge regarding the pineal gland. This hormone is not only related to the circadian control but also influences other behavioral functions such as the reproductive cycle and thermoregulation. In this study the morphology of the pineal gland (epiphysis cerebri) from 20 dogs were analyzed by means of macroscopic and microscopic evaluation. The shape of the gland ranged from conic to "tongue-like shape" (in relation to human tongue). The gland color ranged from beige to gray-brownish and it had a gelatinous consistency. The width and length of the glands ranged from 1.38 to $2.39 \mathrm{~mm}$ and 1.53 to $2.96 \mathrm{~mm}$, respectively. Capsule, septa, pinealocytes, glial cells and pigment granules were microscopically found in all glands. No calcareous concretions were observed.

Key words: Dog, pineal, pinealocytes, glial cells, macroscopic, microscopy
\end{abstract}

1 Departamento de Clínicas Veterinárias - Universidade Estadual de Londrina. Endereço para correspondência: Rua Afonso Pena, 326; Bairro: Residencial do lago II; Londrina-PR; CEP: 86062 - 140. E-mail: lagomes@uel.br

2 Professora Titular Aposentada - Faculdade de Medicina Veterinária e Zootecnia da Universidade de São Paulo, Departamento de Cirurgia (VCI), Setor de Anatomia dos Animais Domésticos e Silvestres.

3 Professor Aposentado do Instituto de Ciências Biológicas, Departamento de Histologia, Embriologia e Citologia, da Universidade de São Paulo.

4 Médica Veterinária Residente do Hospital Veterinário da Universidade Estadual de Londrina.

5 Senior Lecturer, Section of Veterinary Pathology, Department of Basic Veterinary Sciences, Faculty of Veterinary Medicine, University of Helsinki, FINLAND.

6 Professor da Faculdade de Medicina Veterinária e Zootecnia da Universidade de São Paulo, Departamento de Cirurgia (VCI), Setor de Anatomia dos Animais Domésticos e Silvestres.

* Autor para correspondência 


\section{Introdução}

Por muito tempo tinha-se a idéia de que a glândula pineal em vertebrados superiores representava apenas um órgão que sofrera atrofia durante a evolução das espécies, tornando-se um apêndice epitalâmico sem muita função. Porém, a descoberta, por Lerner et al. em 1958, de que a pineal produz um hormônio, a melatonina, abriu um vasto campo para pesquisas relacionadas à sua fisiologia. Este hormônio está envolvido com o controle circadiano e outras funções comportamentais fisiológicas como o ciclo reprodutivo, termorregulação e tolerância termal (TILDEN; HUTCHINSON, 1993). Kitay e Altschule (1954) relatam casos clínicos em que a presença de tumores da pineal em crianças leva a um desenvolvimento sexual precoce do indivíduo, mostrando assim um possível papel antigonadotrófico deste órgão. Reforçando este aspecto, Machado (1993) relata que há um consenso de que pelo menos em mamíferos a pineal tem uma atividade inibidora sobre as gônadas e que em muitos vertebrados e possivelmente no homem participa da regulação dos ritmos circadianos.

Relativo ao histórico da pineal, Binkley (1988) comenta que aqueles que escreveram a sua história não se detiveram apenas a uma cronologia, mas também a dividiram em épocas. Kappers apud Binkley (1988), dividiu os avanços nas pesquisas da pineal em três eras, enquanto que Altschule (apud BINKLEY, 1988, p.4) sugeriu quatro períodos históricos. Kappers (1965), assim como Altschule (1975), incluiu na primeira fase o que ele chamou de "noções supersticiosas", idéias pré-Cartesianas e pós-Cartesianas, a descoberta da pineal e elucubrações sobre a possível função da pineal (300 a.C. até o fim do século XIX). A segunda era, "estudos preliminares", foi guiada por avanços técnicos em microscopia. Durante este período havia pesquisadores estudando a anatomia, histologia e embriologia comparadas da pineal $\left(1^{\mathrm{a}}\right.$ metade do séc. $\mathrm{XX}) . \mathrm{Na} 3^{\mathrm{a}}$ era (KAPPERS) ou $3^{\mathrm{a}}$ e $4^{\mathrm{a}}$ eras (ALTSCHULE), com novas investigações houve avanços no campo da fisiologia e farmacologia ( $2^{\mathrm{a}}$ metade do séc. XX) da pineal, tendo sido ela funcionalmente relacionada a outras estruturas do corpo. A grande descoberta para estes estudos foi o reconhecimento de que o ciclo de luz e escuridão era um fator importante no mecanismo de funcionamento da pineal. Bainard apud Binkley (1988), identificou o período de 1954 a 1965 como a "década da transformação" quando "a glândula pineal foi demonstrada como sendo um transdutor neuroendócrino ativo em contraste com a proposta de períodos anteriores em que ela teria uma função vestigial".

Especificamente quanto à anatomia da pineal no cão, Hullinger (1993) comenta que ela é uma pequena excrescência, ímpar, de coloração creme, em forma de cunha, situada na linha mediana sobre o diencéfalo. Quanto aos aspectos microscópicos da glândula, este mesmo autor comenta que o parênquima da pineal é composto por endocrinócitos pineais, envolvidos por neurofilamentos. Há ainda os gliócitos centrais que são células de sustentação. Relata que a piamater promove um limite para o tecido glandular e que moderada quantidade de tecido conjuntivo é encontrado junto à cápsula, seus septos e trabéculas. Por este estroma, cursam vasos sangüíneos e fibras simpáticas pós-ganglionares. Por outro lado, existem dados específicos sobre a anatomia do cão que sequer referem-se à pineal, a exemplo de material elaborado por Anderson (1994) e Adam et al. (1970). Em outros casos, trabalhos recentes sobre a ultraestrutura da pineal nesta mesma espécie como o de Calvo et al. (1988), tem buscado melhor conhecimento deste órgão, porém deixando ainda uma lacuna no atinente a aspectos de sua anatomia macro e mesoscópica. Talvez o fato de publicações sobre anatomia não trazerem fotografias sobre a pineal do cão, esteja ligado à própria localização e acanhada representação anatômica desta estrutura.

Assim, surgiu nosso interesse em enfocar mediante estudo sistemático, tais aspectos, propondonos a: mensurar o comprimento e a largura da glândula e do encéfalo; mensurar o perímetro da glândula; efetuar cortes histológicos longitudinais e transversais da pineal. 


\section{Revisão de Literatura}

\section{Considerações Gerais}

Segundo Schaffer, Symington e Bryce (1909) a glândula pineal está presente em todos os vertebrados exceto nos anfioxos. Para Vollrath (1981), um órgão pineal propriamente dito está ausente em crocodilianos, edentatas e sirênios, porém células pineais principais sempre são identificadas entremeadas por células gliais, tecido conjuntivo e vasos como um complexo pineal disperso.

Machado (1993) relata que a pineal humana origina-se embriológicamente de um divertículo ependimário no tecto do terceiro ventrículo, formando-se assim um saco revestido de epêndima em comunicação com a cavidade ventricular. Segundo este mesmo autor, nos peixes, anfíbios e alguns répteis, este saco permanece como tal e as células ependimárias de sua parede diferenciam-se em fotorreceptores que se assemelham aos cones e bastonetes da retina. Assim, nesses vertebrados inferiores, a pineal é um órgão sensorial que recebe os estímulos luminosos que atravessam a pele e o crânio. Já nas aves e mamíferos, as células ependimárias que formam o divertículo embrionário multiplicam-se, obliterando a luz do divertículo. Estas células diferenciam-se nas células parenquimatosas do corpo pineal ou pinealócitos. Deste modo, durante a evolução, o corpo pineal passou de um órgão sensorial para um órgão parenquimatoso e secretor. Este mesmo autor comenta que em alguns vertebrados inferiores existe, além do corpo pineal, o órgão parapineal, situado próximo à pineal e muito variável. Em alguns lagartos ele constitui o chamado terceiro olho, que é impar e mediano localizado entre os dois olhos laterais.

Lerner (1962), em tratado sobre endocrinologia humana, comenta que em alguns animais de sangue frio a glândula pineal é um órgão fotorreceptivo, e que seu papel é determinado de acordo com a quantidade de exposição à luz à qual o animal é submetido. Refere ainda que em alguns vertebrados inferiores, o aparato pineal é tão diferenciado que parte dele torna-se um olho, o chamado terceiro olho, que não está presente nos vertebrados superiores.

Bargmann (1943) destaca-se entre os autores consultados, não apenas porque tratou da anatomia microscópica do órgão pineal na maioria dos vertebrados, mas também por ter dedicado um capítulo especial para as dependências das estruturas microscópicas da pineal dos mamíferos sobre diferentes condições, internas e externas, a que os animais eram submetidos. De acordo com este autor, o órgão pineal mudou da forma fotorreceptora para um órgão excretor. As células fotossensoriais foram perdendo suas organelas e desenvolvendo dentro dos pinelócitos dos mamíferos, estruturas secretoras.

Um acontecimento de grande importância foi a descoberta da melatonina por Lerner (1958), o que incentivou ainda mais a nova era de pesquisas sobre esta glândula pineal. O hormônio melatonina ( $\mathrm{N}$-acetil5-metoxitriptamina), produzido na glândula pineal dos vertebrados, está envolvido com o controle circadiano e outras funções comportamentais fisiológicas como o ciclo reprodutivo, termorregulação e tolerância termal (TILDEN; HUTCHINSON, 1993).

Quanto à inervação, Arendt apud Oliveira (1998), afirma haver evidências de que a pineal receba múltiplos sistemas de inervação, seja de origem exógena, como inervação simpática periférica, seja direta através do sistema nervoso central, uma vez que já fora detectado a presença de neurotransmissores como o peptídeo intestinal vasoativo, arginina-vasopressina, oxitocina, entre outros. Pensava-se que as projeções do SNC iam até o pedúnculo sem atingir a pineal, passando para a comissura posterior, mas a presença dos neurotransmissores na glândula evidencia a inervação central. Constituindo-se no nervo do conário, o único ou duplo, as fibras nervosas periféricas vêm da região da tendo do cerebelo e penetram nas faces dorsal ou dorso lateral da pineal. Estas fibras periféricas simpáticas são originadas nas células do gânglio cervical superior e correm subendotelialmente na parede do seio reto. Esta via parte da retina e pela 
projeção retino-hipotalâmica atinge o núcleo paraventricular, sendo que este funciona como uma estação intermediária neste circuito.

Blin e Maurin (1956), em estudo sobre a pineal dos animais domésticos, relatam que ela pode ser classificada baseando-se na sua localização, sendo a região posterior do corpo caloso (esplênio), usada como ponto de referência. Assim, as pineais serão supracalosa, subcalosa e pós-calosa. De acordo com esta classificação, a posição subcalosa é encontrada em canívoros e primatas, enquanto a posição póscalosa é presumidamente típica na vaca, no cavalo, no burro, na mula, na ovelha e no bode (BLIN; MAURIN apud VOLLRATH, 1981, p.12; FRAUCHIGER apud VOLLRATH, 1981, p.12).

Reiter (1981) comenta que a pineal dos mamíferos possui uma ampla variação anatômica e que em virtude disso foram criados vários sistemas para classificá-la quanto à sua forma, tamanho e localização e que a classificação que parece ter maior versatilidade e aplicabilidade é a que foi proposta por Vollrath em 1981. Para Oksche apud Vollrath (1981), a glândula deve ser classificada apenas pelo seu formato: alongado, cônico ou em forma de pêra. Sendo assim, o autor propõe uma classificação mais completa da pineal tomando como base sua relação com o terceiro ventrículo, envolvendo também a forma e o arranjo do tecido deste órgão. Neste sistema, ele classifica a pineal como tipo proximal ou tipo A se a maior parte do volume deste órgão estiver próxima ao terceiro ventrículo. Se a pineal é alongada, se o comprimento do órgão for em torno de ou ligeiramente maior que duas vezes a maior largura, ela é classificada como tipo próximo-intermediário, designado como tipo AB. Se a pineal é muito longa e uma quantidade substancial de tecido pineal encontrase relacionado ao cerebelo, ela pertence ao tipo próximo-intermédio-distal ou tipo ABC. Se qualquer uma dessas partes está substancialmente reduzida em quantidade, as letras maiúsculas são trocadas por letras minúsculas do alfabeto grego. Por exemplo, no tipo $\alpha \mathrm{BC}$, a porção proximal está presente, porém em tamanho reduzido. Se uma região está ausente, a letra correspondente é omitida. Se não existem estruturas delimitadas que permitam a classificação do órgão, esta pineal recebe a sigla de difusa (diff) subscrita após as letras. Se a pineal se encontra dentro do ventrículo recebe a sigla de intraventricular (iv). Se for identificada uma concavidade, como no caso de alguns marsupiais, leva a sigla de côncava (hollow).

\section{Anatomia e histologia}

Dentre os tratadistas de medicina humana, quanto à anatomia da glândula pineal, citamos a exemplo Erhart (1968) e Machado (1993), que relatam que a pineal humana está localizada na fissura formada pelo encontro do cerebelo e dos hemisférios cerebrais; ela é ímpar, possui formato piriforme e prende-se às comissuras habenular e posterior.

Quanto à histologia da glândula pineal humana, segundo Junqueira e Carneiro (1999), predominam dois tipos celulares, os pinealócitos e os astrócitos. Estas células apresentam-se nas lâminas coradas pela hematoxilina-eosina com o citoplasma claro e grandes núcleos esféricos. Constituem 95\% das células da pineal. A impregnação pela prata segundo o método de Del Rio Hortega mostra que os pinealócitos possuem numerosas ramificações com as extremidades dilatadas. O citoplasma dos pinealócitos contém moderada quantidade de ribossomos, pouco retículo endoplamático rugoso, mas o retículo endoplasmático liso é desenvolvido e o citoplasma contém numerosas vesículas de função desconhecida. O citoplasma apresenta feixes de microtúbulos, mais freqüentes nos prolongamentos. Entre os pinealócitos com seus núcleos grandes e esféricos, observam-se núcleos alongados e mais fortemente corados, que pertencem aos astrócitos. Como tecido nervoso, estes astrócitos possuem prolongamentos e grande quantidade de filamentos intermediários. Os astrócitos constituem $5 \%$ do parênquima da pineal. Cita o autor que, Acervuli cerebri ou areia cerebral, é o nome dado às concreções de fosfato e carbonato de cálcio encontradas normalmente na pineal do adulto e que 
esta aumenta com idade. Estas concreções se localizam no material extracelular do tecido conjuntivo. São importantes nos estudos radiológicos, pois tornam a pineal bem visível uma vez que são material radiopaco. A calcificação da pineal não impede sua atividade, porque mesmo na idade avançada, quando o acúmulo de concreções é maior a glândula funciona normalmente, a julgar pelas substâncias ativas e enzimas nela presentes.

Yong e Heath (2001) relatam que a pineal humana é constituída de dois tipos principais de células: os pinealócitos e as células neurogliais. Os pinealócitos são neurônios altamente modificados dispostos em aglomerados e cordões circundados por uma rica rede de capilares fenestrados, possuem núcleos arredondados com nucléolos proeminentes, citoplasma granular e muitos prolongamentos altamente ramificados, alguns dos quais terminam junto ou sobre os vasos sangüíneos. Quanto às células neurogliais, os autores comentam que ela são semelhantes aos astrócitos do resto do sistema nervoso central, estão dispersas entre os aglomerados de pinealócitos e em associação a capilares.

Dentre os tratados de medicina veterinária, quanto à anatomia da glândula pineal podemos citar autores como Dyce, Sack e Wensing (1987) que descrevem esta estrutura nos animais domésticos como uma pequena excrescência pigmentada de forma escura, consistência sólida, e é um componente da face dorsal do encéfalo, localizada na extremidade caudal do teto do terceiro ventrículo e imediatamente anterior aos colículos rostrais. No encéfalo intacto, ela situa-se oculta entre os hemisférios cerebrais e o cerebelo.

Especificamente no cão, Hullinger (1993), relatam que a glândula pineal constitui uma pequena estrutura ímpar, de coloração creme, e que se localiza na região caudal do teto do terceiro ventrículo. Relatam que ela cresce tomando um formato de pólipo e estendese caudalmente através do espaço que existe entre o cerebelo e os hemisférios cerebrais. Estes mesmos autores relatam que o tamanho da pineal é de aproximadamente $3 \mathrm{~mm}$ de comprimento, $1,5 \mathrm{~mm}$ de largura e $1 \mathrm{~mm}$ de espessura.
Venzke (1986) relata que a pineal do cão encontrase cranialmente aos colículos rostrais e imediatamente caudal ao corpo habenular. Ela é pequena e alongada, em forma de lança e tem coloração cinzaesbranquiçada. No cão adulto tem cerca de $2 \mathrm{~mm}$ de comprimento.

Blin e Maurin (1956) relatam que no cão a pineal é muito pequena e por muito tempo foi ignorada pelos pesquisadores, nesses animais. Comentam que ela possui forma piramidal, consistência gelatinosa e pode variar de coloração quase transparente até rósea e que seu pedúnculo não é visível e seu corpo se une diretamente à comissura habenular. Descrevem que as medidas quanto ao comprimento e a largura são respectivamente de $0,40 \mathrm{~cm}$ e $0,30 \mathrm{~cm}$. Zach apud Vollrath (1981) relata que a pineal no cão mede 3,1 $\mathrm{mm}$ de comprimento e 1,2 $\mathrm{mm}$ de largura.

Quanto aos tratadistas que comentam sobre o aspecto microscópico da glândula pineal no cão, podemos citar Hullinger (1993), que mediante o método de coloração pentacromático, observaram que a pineal do cão contém células denominadas de endocrinócitos pineais (pinealócitos), que se encontra em maior número em relação às células de sustentação ou gliócitos centrais. A pia-mater recobre toda a glândula e há uma delicada cápsula que possui moderada quantidade de tecido conjuntivo, e esta envia septos e trabéculas para o interior da pineal. Acompanhando estas estruturas, cursam os vasos sangüíneos e fibras simpáticas pós-ganglionares.

Banks (1986), em seu livro sobre histologia veterinária aplicada, descreve que a pineal nos animais domésticos é coberta por um tecido conjuntivo da pia-mater, e que septos e lobulações do órgão são acompanhados por este mesmo tipo tecidual. Em relação aos componentes celulares, os autores relatam à presença de pinealócitos e astrócitos, e eventualmente podem-se encontrar fibroblastos, plasmócitos, mastócitos e macrófagos. Os pinealócitos são o tipo celular predominante e possuem um núcleo aberto, grande e redondo, estando situado em um citoplasma acidofílico. Os astrócitos são típicos e estão situados entre o tecido 
vascular e os pinealócito. Segundo estes mesmos autores, a pineal contém concreções calcáreas chamadas de corpora arenacea, que parecem ter uma origem glial ou estromal e sua estrutura possui cristais de hidroxiapatita.

Ellsworth, Yang e Ellsworth (1985) estudaram as pineais de 9 cães da raça beagle através de histologia empregando como método de coloração a eosinahematoxilina, e descreveram a presença de células ependimárias observadas usualmente na margem, e pinealócitos e células da glia no centro da pineal. Em algumas glândulas, encontrou-se fazendo parte da composição da cápsula, epitélio colunar ou cubóide de um lado e epitélio simples do outro. Estes mesmos autores comentam que não há lobulações e sim grupos de pinealócitos dando origem a formações não bem definidas, semelhantes a ácinos. Estas estruturas são rodeadas por espaços de tecido conjuntivo. Ao redor da periferia da glândula há pequenas arteríolas e no interior há predomínio de capilares. Os processos citoplasmáticos das células da glia e pinealócitos encontram-se próximos aos vasos sangüíneos. As células parenquimatosa não possuem formato uniforme e contém um núcleo vesicular de vários tamanhos com cromatina dispersa, porém de aspecto granular em alguns casos. O citoplasma destas células possui uma coloração rosa claro, com prolongamentos às vezes evidentes. Nucléolo único fora usualmente identificado, embora em alguns casos seja duplo. Estes autores ainda descrevem que alguns núcleos escuros foram observados e que podem ser linfócitos ou células da glia. Comentam que em trabalhos prévios não relataram à presença de concreções calcáreas na pineal do cão e que eles também não encontraram esta estrutura. Como aspecto importante, ressaltam que o tamanho da pineal variou individualmente nos nove cães estudados.

Calvo et al. (1988) realizaram trabalho com 12 cães sem raça definida, sendo todos adultos e de ambos os sexos em que estudaram a estrutura e ultraestrutura das células da pineal do cão, tendo como principal objetivo, avaliar o tipo de pigmento presente nestas células. Para microscopia de luz, estes autores utilizaram o método de coloração de prata de Masson Fontana, e também se utilizou tratamento com hidróxido de hidrogênio e ácido peracético. Neste estudo, encontrou-se pigmento em todas as pineais analisadas e confirmou-se que este era melanina.

\section{Material e Método}

Para este estudo utilizamos um total de 20 cães, sendo 14 fềmeas e 6 machos, (14 sem raça definida, 2 pastores alemães, 1 doberman pinscher, 2 dogues alemães e 1 doberman). Desses 20 animais, 12 foram destinados ao estudo macro e mesoscópico e os outros 08 foram utilizados para estudo microscópico da glândula pineal.

Quanto ao local de obtenção dos animais para a pesquisa, 15 deles foram provenientes do Serviço de Clínica Médica da Faculdade de Medicina Veterinária e Zootecnia da Universidade de São Paulo (FMVZ-USP) e o outros 5 animais foram obtidos através do Centro de Controle de Zoonoses (CCZ) da cidade de São Paulo, Estado de São Paulo. Todos esses animais foram encaminhados para nosso local de trabalho - Laboratório de dissecção do Departamento de Cirurgia (VCI-FMVZ-USP) já em óbito.

Um pré-requisito para a colheita do material para nossa pesquisa é que os cães envolvidos no estudo não deveriam possuir sinais clínicos ligados a alterações do sistema nervoso central.

\section{Macroscopia}

Para a análise macroscópica, os encéfalos ainda a fresco foram acessados através de uma incisão em correspondência à linha mediana na cabeça, sendo a pele rebatida juntamente com a musculatura da região temporal. Então, com auxílio de uma serra presa em arco realizava-se uma abertura na calota craniana em forma retangular envolvendo os ossos frontal e parietal. Esta abertura, em seguida, era ampliada com o auxílio de um alicate. Uma vez 
exposto, o encéfalo era retirado, preservando-se o máximo possível suas estruturas, desde o bulbo olfatório até a medula oblonga. Os encéfalos foram isolados num período que variou de 20 a 60 minutos após a morte dos animais, sendo então realizada uma incisão correspondente à fissura longitudinal do cérebro para alcançar e seccionar o corpo caloso, separando completamente os hemisférios cerebrais, para uma melhor exposição e contato da pineal com a solução de formoldeído a $20 \%$, na qual foram submersos. O estudo macroscópico somente foi iniciado, depois de um período mínimo de 48 horas em relação à data da imersão dos encéfalos. Em seguida mensuramos o comprimento das pineais e sua largura (tomando como base para esta última medida a porção mais larga da pineal) com um paquímetro eletrônico digital STARRET ${ }^{\circ}$, cat. $n^{\circ}$ 727-6/150, curso $150 \mathrm{~mm} / 6$, "resolução $0,001 \mathrm{~mm}$ E. 0,005 ”. Realizamos também com este instrumento as medidas referentes ao comprimento e largura do encéfalo tomando como parâmetros para estimar o comprimento, a extremidade rostral do lobo frontal e a região de transição entre o bulbo e a medula espinhal e, para a largura, o ponto de encontro entre a fissura silviana e o sulco rinal lateral, em ambos os antímeros.

\section{Microscopia}

Para a análise microscópica, os encéfalos forma retirados através do mesmo método utilizado na macroscopia e a colheita das pineais foi realizada num período que variou de 15 a 120 minutos após o óbito.. Uma vez exposta a pineal, procedia-se à retirada de um pequeno bloco em formato cúbico, de tecido do diencéfalo com dimensões de aproximadamente $1 \mathrm{~cm}^{3}$, no qual encontrava-se a pineal. Este material era imediatamente acondicionado em solução de McDowell (paraformoldeído a $1 \%$ + glutaraldeído a $4 \%$ em solução tampão fosfato $0,1 \mathrm{M}$, ph 7.4 mantido em temperatura de geladeira). Após um período de fixação de no mínimo 24 horas, este material foi submetido ao procedimento usual de inclusão em parafina. Então foram realizados cortes longitudinais e transversais de $5 \mu$ de espessura e as lâminas foram devidamente montadas e coradas com eosinahematoxilina para análise em microscópio.

\section{Análise estatística}

Foram calculadas as médias e medianas referentes aos resultados obtidos pela mensuração do comprimento, largura e perímetro dos encéfalos e das pineais; foram calculados os coeficientes de correlação (r) entre aos variáveis (comprimento e largura) analisadas e aplico o Teste - T para verificar se os coeficientes eram diferentes de zero, utilizandose o programa estatístico Statigraphics 7.0.

\section{Documentação fotográfica}

As fotografias referentes ao aspecto macroscópico da pineal foram obtidas mediante ao uso de uma câmera digital Sony DSC - F 717 Cybershot. As fotografias referentes ao aspecto microscópico foram realizadas em um microscópio Olimpus BX 60.

\section{Resultados}

Os resultados foram obtidos a partir das seguintes etapas:

\section{Macroscopia}

A análise macroscópica foi realizada através das medidas da glândula pineal (comprimento e largura) e do encéfalo correspondente (comprimento e largura) bem como da observação da pineal quanto à sua localização, posicionamento, forma e consistência.

A pineal nos cães estudados apresentou-se situada em relação ao teto do III ventrículo, rostralmente aos colículos rostrais, e na linha mediana em relação ao encéfalo (Figura 1). 


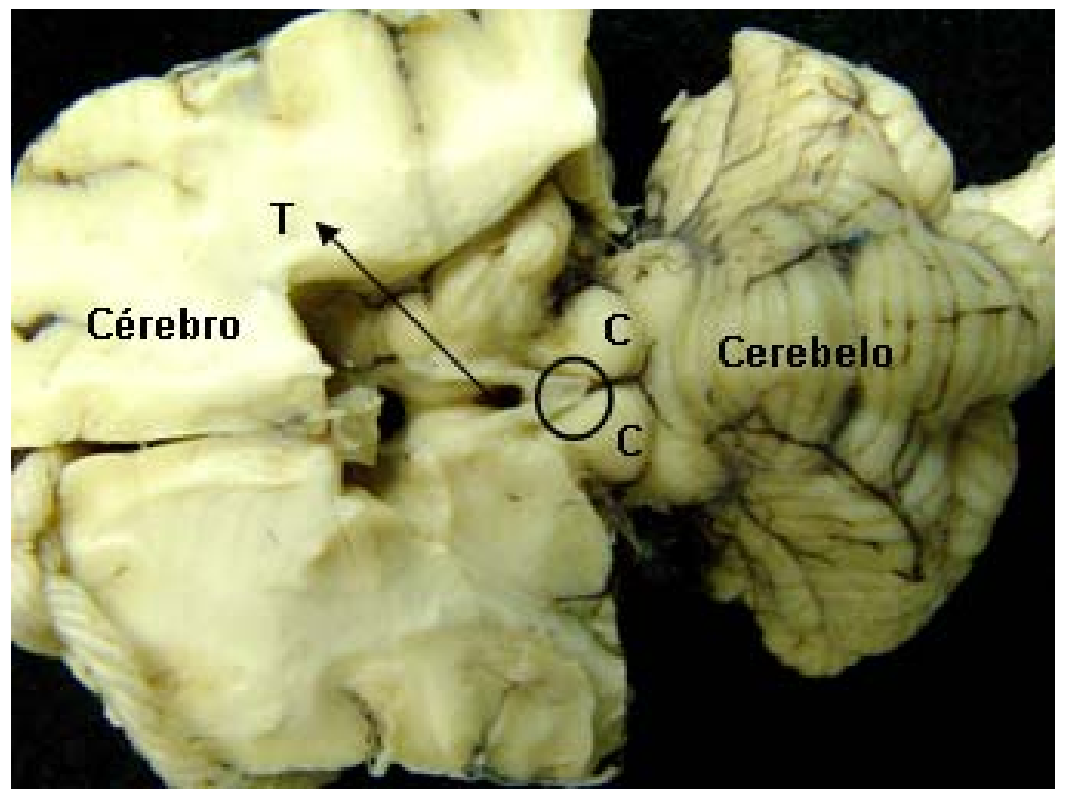

Figura 1. Fotografia de corte longitudinal dos hemisférios cerebrais em vista dorsal destacando-se no círculo a glândula pineal e sua relação com os colículos rostrais (C) e o terceiro ventrículo (T).

Sua coloração variou de bege ( 8 animais - 66,66\% dos casos) a castanho-acinzentado (4 animais $33,33 \%$ dos casos). Sua forma avaliada numa vista dorsal foi predominantemente triangular, o que ocorreu em 10 animais (83,33\% dos casos) e em 2 animais (16,66\% das pineais estudadas). A forma tridimensional das pineais avaliadas foi glossóide (semelhante a uma "língua humana") em 11 animais (91,66\%), sendo que em 1 animal (8,33\%) ela apresentou-se semelhante a um cilindro, com o ápice terminando em bisel.

A consistência das glândulas pineais estudadas foi gelatinosa em $100 \%$ dos animais analisados.

O comprimento dos encéfalos variou de $60,15 \mathrm{~mm}$ a $86,27 \mathrm{~mm}$ com média de $70,05 \mathrm{~mm}$ e mediana de $66,64 \mathrm{~mm}$.

A largura dos encéfalos estudados variou de 31,31 $\mathrm{mm}$ a 43,48 $\mathrm{mm}$ com média de $36,65 \mathrm{~mm}$ e mediana de $36,51 \mathrm{~mm}$.

O comprimento das pineais variou de $1,53 \mathrm{~mm}$ a 2,96 mm com média de 2,05 mm e mediana de $1,97 \mathrm{~mm}$.

A largura das pineais variou de $1,38 \mathrm{~mm}$ a 2,39 $\mathrm{mm}$ tendo média de $1,78 \mathrm{~mm}$ e mediana de $1,69 \mathrm{~mm}$.
Tendo sido calculados os coeficientes de correlação (r) entre as variáveis analisadas e aplicado o Teste - T, verificou-se que não há correlação entre as variáveis, ou seja, tamanho do encéfalo (comprimento e largura) correspondente. Os coeficientes de correlação (r) são: $\mathrm{r}(\mathrm{CE} / \mathrm{CP})=0,2131$; $\mathrm{r}(\mathrm{LE} / \mathrm{LP})=0,1199 ; \mathrm{r}(\mathrm{CE} / \mathrm{PP})=0,1141 ; \mathrm{r}(\mathrm{LE} / \mathrm{PP})=$ 0,1289 , todos não significativos estatisticamente.

\section{Microscopia}

A análise microscópica revelou dois tipos celulares presentes no órgão: pinealócitos e células da glia (possivelmente astrócitos). Os pinalócitos predominaram, estando presentes em todo o parênquima glandular e com maior concentração à medida que se caminha em direção ao centro e à base da glândula. Mostram face aberta, com núcleos grandes, basofílicos, sendo alguns claros e outros mais escuros. A cromatina é granulosa com nucléolo bem evidente, e o citoplasma tem coloração acidófila. Os pinealócitos demonstraram, em alguns casos, disposição tendendo a formar um ácino e, em outros casos formaram arranjo em forma de cordão (Figura 2). 


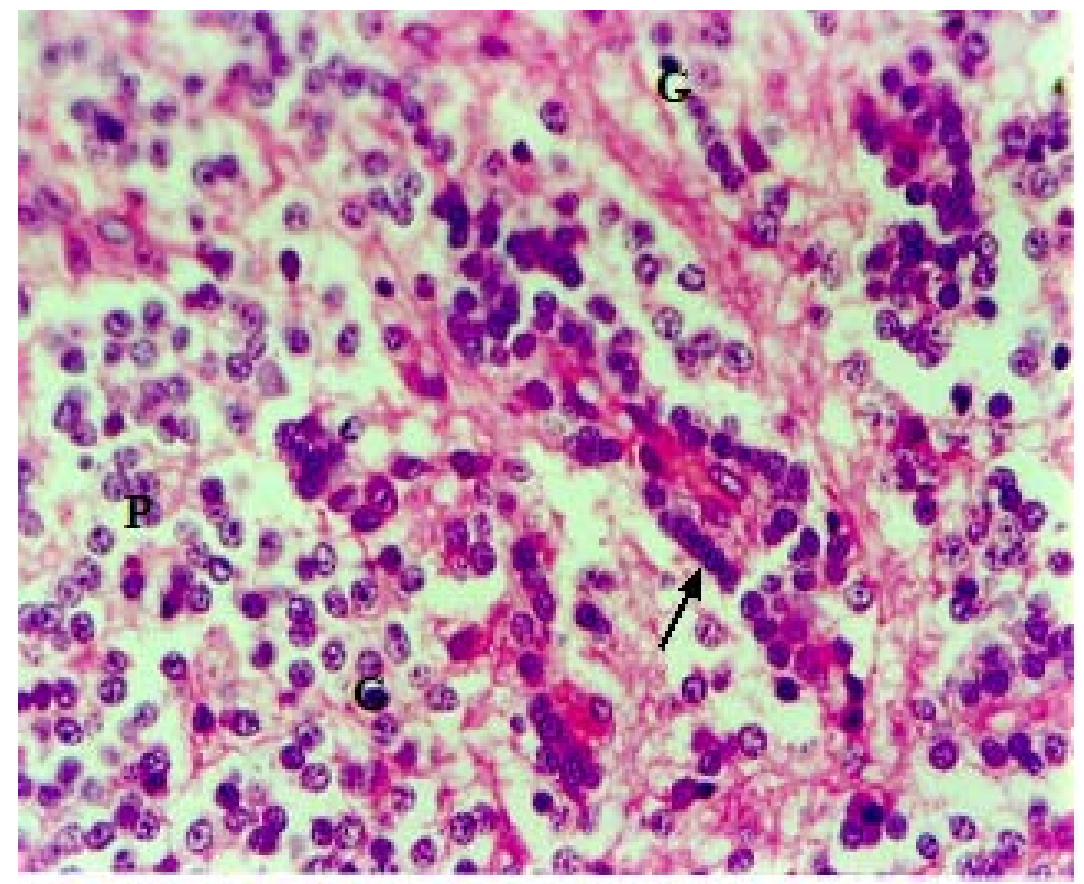

Figura 2. Fotomicrografia em corte transversal demonstrando tecido da glândula pineal - coloração HE. Os pinealócitos (P) encontram-se algumas vezes em arranjos perivasculares formando cordões $(\rightarrow)$ e estão em maior número em relação às células da glia $(\mathbf{G})$.

Observou-se a presença de neuróglia, com células com núcleos escuros (mais escuros que dos pinealócitos), contendo cromatina condensada e citoplasma acidófilo.

Há uma cápsula de tecido conjuntivo que reveste a pineal, e sua característica delicada sugere que ela seja formada pela pia-máter. Esta quando analisada na região da base da glândula, revela um epitélio prismástico, colunar ou cilíndrico com a presença de cílios que estão voltados para o recesso pineal, que está em comunicação com o terceiro ventrículo, e à medida que se desloca em direção ao ápice da epífise, este epitélio torna-se cúbico tendendo a pavimentoso. Em todas as pineais analisadas não foram encontrados depósitos de material calcáreo, as chamadas concreções calcáreas, areia cerebral ou acervuli. Vasos sangüíneos foram encontrados dentro e fora do parênquima glandular, havendo um predomínio destes nas regiões mais superficiais da pineal.

Em $2(25 \%)$ das 8 pineais análisadas histologicamente, encontramos pequenas regiões com manchas de coloração castanho escuro que possivelmente são referentes a pigmentos de melanina.

\section{Discussão}

Em nossas primeiras dissecações, surpreendeunos o pequeno tamanho da pineal, em todos os casos. Surpreendeu-nos, também, o fato de encontrarmos glândulas muito pequenas em encéfalos de cães de grande porte e, por outro lado, glândulas não tão pequenas em encéfalos de cães de pequeno porte. Tivemos então a curiosidade de avaliar as dimensões de cada pineal (comprimento, largura e perímetro) e de cada encéfalo correspondente (comprimento e largura) para confrontá-las estatisticamente.

A análise que efetuamos, revelou-nos que as dimensões da pineal do cão, não possuem relação com o tamanho do encéfalo. Provavelmente isso ocorra pelo fato da pineal estar envolvida com um grande número de fatores que não foram foco do nosso estudo, mas que abrem caminho para novos trabalhos, como por exemplo, idade dos animais, sexo, período reprodutivo das fêmeas, condições de manejo, alterações hormonais, raça e estados patológicos.

Quanto à anatomia macroscópica, as pineais mostraram-se localizadas na região de encontro das 
habênulas, no teto do diencéfalo (porção caudal do III ventrículo), com direcionamento (da base para o ápice) em sentido dorso-caudal. Estas observações estão de acordo com o relatado em tratados de medicina humana e veterinária, por autores como Machado (1993), Dyce, Wensing e Sack (1989), Venzke (1975), Hullinger (1993) e outros. Quanto à coloração, ela variou entre bege, marrom escuro, branco acinzentado e um branco perláceo e sua consistência foi gelatinosa em todas as pineais analisadas. A forma tridimensional das epífises respeitou um padrão cônico e muitas vezes tenderam a glossóide (em relação à língua humana). Em vista dorsal, as pineais revelaram uma forma triangular ou semelhante a "ponta de uma lança". Esses dados são corroborados quando comparados com os de autores que estudaram a pineal do cão, como Blin e Maurin (1956) que relatam que a pineal nos cães é muito pequena e por muito tempo fora ignorado pelos autores nesses animais. É de forma piramidal e gelatinosa. Quanto à coloração, estes mesmos autores comentam que ela é de transparente a rósea, o que não está em concordância com nossos achados; talvez isso se deva ao fato de termos esperado a fixação do material em solução de formol a $20 \%$, para posteriormente realizarmos a análise macro e mesoscópica. Não só devido a isso, mas há fatores outros já citados que podem ter influenciado nessa coloração. Além do mais, os autores acima citados, não comentam se sua análise fora feita após fixação do material ou a fresco. Quanto ao comprimento e largura da pineal, os autores comentam que ela possui respectivamente $4 \mathrm{~mm}$ e $3 \mathrm{~mm}$. Isso difere também de nossos achados, em que o comprimento da pineal teve média de 2,04 mm e mediana de $1,97 \mathrm{~mm}$; a largura apresentou média de 1,78 mm e mediana de 1,69 mm.

Assim sendo, quando confrontamos nossos dados com os de autores como Blin e Maurin (1956), notamos que as pineais de nossos estudos apresentaram-se aproximadamente duas vezes menores. Quando comparamos em relação aos dados de Zach (apud VOLLRATH, 1981, p.17), verificamos que quanto ao comprimento, as epífises dos cães envolvidos em nosso trabalho mostraram-se iguais ou menores e quanto à largura, revelaram-se maiores.

Ellsworth, Yang e Ellsworth (1985), não direcionaram seus estudos para as dimensões da pineal, entretanto ressaltam que ela variou em tamanho nos nove cães estudados e que o diâmetro desta foi menor ou igual a $1 \mathrm{~mm}$, divergindo assim dos dados exibidos por Venzke e Gilmore (1940) e Zach (1960). Quando confrontamos nossos resultados com o de Ellsworth, Yang e Ellsworth (1985), embora não tenhamos mensurado o diâmetro das pineais, e sim seu perímetro, notamos que as epífises dos cães de nosso estudo, possuem diâmetro provavelmente maior que o acima relatado; talvez isso se deva ao fato destes autores terem utilizado somente cães da raça beagle, filhotes e também pelo fato dos animais terem sido confinados de junho a agosto num laboratório climatizado.

Quanto ao posicionamento da pineal, Blin e Maurin (1956) propõem uma classificação baseada no posicionamento desta em relação ao esplênio do corpo caloso, podendo ser, portanto: supracalosa, subcalosa e pós-calosa. A dos cães envolvidos em nosso estudo mostrou-se subcalosa, um dado que corrobora com os estudos dos autores acima citados, pois estes relatam que a pineal dos carnívoros e dos primatas é subcalosa. Já na classificação proposta por Vollrath (1981), ele comenta que as pineais que são alongadas e demonstram um comprimento em torno de ou ligeiramente maior que duas vezes a maior largura, são classificadas como sendo do tipo próximo-intermediário ou $\mathrm{AB}$, e que a pineal dos cães pertence a este tipo; nossos dados estão em concordância com a classificação proposta pelo autor em relação a espécie canina.

Oksche (1965) propõe que a pineal deve ser classificada apenas quanto ao seu formato: alongado, cônico ou em forma de pêra. Quando confrontamos nossos achados como esta classificação, podemos inferir que nos cães estudados, a pineal mantém um padrão em formato cônico, porém verificamos que grande parte das glândulas demonstrou um formato 
muito semelhante à língua humana, ou seja, glossóide, não sendo por excelência um cone perfeito.

Desta maneira, podemos verificar que a maioria das espécies envolvidas nesta discussão, em maior ou menor proporção, apresentou em comum o posicionamento, a localização na linha mediana do encéfalo e a coloração que se enquadra num tom castanho ou ligeiramente amarronzado, chegando a ter uma mistura entre marro-acinzentadaesbranquiçada.

A análise histológica em nosso estudo demonstrou a presença de pinealócitos, sendo que estes estão em maior número, e células da glia, estas em menor número e que segundo a literatura são provavelmente astrócitos; porém só poderíamos afirmar isso se tivéssemos utilizado coloração específica para evidenciar este tipo celular. Além disso, os linfócitos na pineal sob a coloração de H.E., aparecem de forma e cor semelhante a dos astrócitos, ficando muito difícil a diferenciação entre estes dois tipos celular quanto esta coloração é empregada. Em alguns casos, os pinealócitos dispuseram-se na vizinhança de vasos sangüíneos formando uma espécie de cordão, e em outros casos, os pinealócitos se agruparam originando uma estrutura semelhante a um ácino, independente de estarem próximos ou não a vasos. Essa disposição provavelmente se deva à função secretora que a pineal possui, lembrando que ela produz e libera o hormônio melatonina, o que lhe conferiu o título de glândula por alguns autores. Porém, não podemos deixar de ressaltar que grande parte dos pinealócitos encontra-se de forma difusa na pineal.

Confrontando nossos dados com a literatura, em relação à pineal humana, podemos citar em concordância com nossos achados, autores como Yong e Heath (2001), além de citarem a presença dos pinealócitos e células da neuróglia na pineal humana em seu tratado, relatam também que os pinalócitos são neurônios altamente modificados dispostos em aglomerados e cordões circundados por uma rica rede de capilares fenestrados, possuem citoplasma granular e muitos prolongamentos altamente ramificados, alguns dos quais terminam junto ou sobre os vasos sangüíneos. Esta última disposição, os aglomerados e os cordões de pinelócitos foram também características observadas nas epífises dos cães envolvidos em nosso estudo. Possivelmente estas disposições que muitas vezes estão próximas a vasos sangüíneos, devam-se a característica de um tecido que está secretando algo, no caso, a melatonina produzida na pineal.

Os autores ainda comentam, que as células da neuróglia são semelhantes aos astrócitos do resto do SNC, estão dispersas entre os aglomerados de pinealócitos e em associação a capilares mais uma vez, essas descrições nos permitem sugerir com mais segurança de que as células da neuróglia observadas nas epífises avaliadas em nosso trabalho sejam astrócitos.

Junqueira e Carneiro (1999) comentam que na pineal predominam 2 tipos celulares, os pinealócitos e os astrócitos. Os primeiros apresentam-se na coloração de H.E. com o citoplasma claro e grandes núcleos esféricos. Constituem 95\% das células da pineal; entre eles observam-se núcleos alongados e mais fortemente corados que pertencem aos astrócitos, que constituem 5\% do parênquima da pineal. Citam os autores, que acervuli cerebri ou areia cerebral é o nome dado às concreções de fosfato e carbonato de cálcio encontradas normalmente na pineal do adulto e que aumentam de número com a idade. Já comentamos que nos cães de nosso estudo estas concreções não foram encontradas; pinealócitos e células de núcleo escuro foram encontradas (possivelmente astrócitos) e eventualmente células com núcleo semelhantes em coloração ao dos pinealócitos, mas com forma diferente, talvez sejam pinealócitos em fase funcional mais ou menos ativa, ou talvez seja um outro tipo celular. Para melhor esclarecer estas dúvidas, um estudo de microscopia eletrônica seria mais fiel.

Em relação a tratadistas que abordam o aspecto da microscopia de luz no cão, como Hullinger (1993) descreve que as células presentes na pineal desta 
espécie são denominadas de endocrinócitos pineais, que se encontram em maior número quando comparadas as células de sustentação ou gliócitos centrais. A piamater recobre toda a glândula e há uma delicada cápsula que possui moderada quantidade de tecido conjuntivo, e esta envia septos e trabéculas para o interior da pineal. Acompanhando estas estruturas, cursam os vasos sangüíneos e fibras simpáticas pós-ganglionares. Em nosso estudo, observamos estas mesmas características, porém como já citamos, a cápsula que recobre a pineal provavelmente é oriunda da piamater, e esta possui um epitélio que varia de colunar/prismático a pavimentoso à medida que caminha da base para o ápice da epífise cerebral.

Banks (1986), em seu livro sobre histologia veterinária aplicada, descrevem que a pineal nos animais domésticos é coberta por um tecido conjuntivo da piamater, e que septos e lobulações do órgão são acompanhados por este mesmo tipo tecidual. Em relação aos componentes celulares, os autores relatam à presença de pinealócitos e astrócitos, e eventualmente podem-se encontrar fibroblastos, plasmócitos, mastócitos e macrófagos. Os pinealócitos são o tipo celular predominante e possuem um núcleo aberto, grande e redondo, estando situado em um citoplasma acidofílico. Estas características foram igualmente observadas nas pineais dos cães que nós estudamos, embora muitas vezes alguns núcleos não se apresentaram com forma totalmente arredondada. Os autores ainda comentam que os astrócitos são típicos e estão situados entre o tecido vascular e os pinealócitos e também mencionam a presença de concreções calcáreas. Em relação aos primeiros nós encontramos células da glia que sugerimos serem astrócitos e a localização destes coincide com o que os autores acima citam, já em relação às concreções calcáreas, elas não foram observadas.

Ellsworth, Yang e Ellsworth (1985), estudaram as pineais de 9 cães da raça beagle por meio da histologia empregando como método de coloração a eosina-hematoxilina, e descreveram a presença de células ependimárias observadas usualmente na margem, e pinealócitos e células da glia no centro da pineal. Em algumas glândulas, encontrou-se fazendo parte da composição da cápsula, epitélio colunar ou cubóide de um lado e epitélio simples do outro. Estes mesmos autores comentam que não há lobulações e sim grupos de pinealócitos dando origem a formações não bem definidas, semelhantes à ácinos. Estas estruturas são rodeadas por espaços de tecido conjuntivo. Ao redor da periferia da glândula há pequenas arteríolas e no interior há predomínio de capilares. Os processos citoplasmáticos das células da glia e pinealócitos encontram-se próximos aos vasos sangüíneos. As células parenquimatosa não possuem formato uniforme e contém um núcleo vesicular de vários tamanhos com cromatina dispersa, porém de aspecto granular em alguns casos. O citoplasma destas células possui uma coloração rosa claro, com prolongamentos às vezes evidentes. Nucléolo único fora usualmente identificado, embora em alguns casos seja duplo.

Estes autores ainda descrevem que alguns núcleos escuros foram observados e que podem ser linfócitos ou células da glia. Comentam que trabalhos prévios não relataram à presença de concreções calcáreas na pineal do cão e que eles também não encontraram esta estrutura. Como aspecto importante, ressaltam que o tamanho da pineal variou individualmente nos 9 cães estudados. Em nosso estudo, os achados corroboram com as citações acima descritas pelos autores, e ressaltamos o fato dos pinealócitos encontrarem-se dispersos por toda a glândula e tendendo a uma maior concentração na região do centro para a base das pineais avaliadas, assim como as células da glia.

Calvo et al. (1988) realizaram trabalho com 12 cães sem raça definida, sendo todos adultos e de ambos os sexos, estudando a estrutura e ultraestrutura das células da glândula pineal do cão, tendo como principal objetivo, avaliar o tipo de pigmento presente nelas. Para microscopia de luz, estes autores utilizaram o método de coloração de prata de Masson Fontana, e também se utilizou tratamento com 
hidróxido de hidrogênio e ácido peracético. Neste estudo, encontrou-se pigmento em todas as pineais analisadas e confirmou-se que estes eram de melanina. Nas pineais envolvidas em nosso trabalho, notamos também a presença de grânulos de coloração castanho escuro ou marrom escuro, que sugerimos serem pigmentos de melanina. Porém, em relação à incidência, nossos dados divergem dos achados citados por esses autores, pois apenas duas das oito glândulas pineais utilizadas para microscopia de luz, apresentaram esta estrutura.

Sendo assim, notamos que muitas perguntas sobre a glândula pineal ainda estão para serem estudadas e que os conhecimentos anatômicos desta estrutura, são fundamentais para um entendimento melhor do seu todo.

\section{Conclusões}

Pelo que acabamos de expor, julgamos poder concluir que:

a) A glândula pineal de todos os cães estudados apresentou-se situada em relação à região posterior do teto do III ventrículo, em correspondência ao plano mediano, inserindo-se por sua base, na região das habênulas (vista dorsal). Têm forma cônica ou glossóide (relativamente à língua humana), sendo que seu corpo e ápice tendem em sentido dorso-caudal descrevendo curvatura de concavidade ventral, em direção aos colículos rostrais (figura 1);

b) O comprimento das glândulas pineais variou de $1,53 \mathrm{~mm}$ a 2,96 mm, com média de 2.04 e mediana de $1,97 \mathrm{~mm}$, enquanto que para a sua maior largura foram registrados valores entre 1,38 $\mathrm{mm}$ e $2,39 \mathrm{~mm}$, com média de $1,78 \mathrm{~mm}$ e mediana de 1,69 mm;

c) Não foi encontrada, estatisticamente, correlação dessas variáveis com o tamanho (comprimento e largura) dos encéfalos correspondentes;

d) As glândulas pineais, em relação à coloração, demonstraram uma variação entre bege e castanhoacinzentado; e) Analisadas quanto à forma, disposição espacial, cor e dimensões, as pineais exibem diferenças individuais de forma a não termos registrado uma igual à outra;

f) As glândulas pineais dos cães estudados inseremse no tipo intermédio-proximal ou $\mathrm{AB}$ da classificação de Vollrath (1981);

g) Histologicamente as glândulas pineais dos cães estudados demonstraram um modelo típico dos mamíferos contendo uma delicada cápsula que emite septos ou trabéculas para o interior do órgão; pinealócitos com núcleo arredondado podendo variar para ovóide, basófilo, com cromatina dispersa e em maior número; células da glia com núcleos escuros e variando de redondo a ovóide; aglomerados de coloração castanho ou marrom escuro (provavelmente pigmentos de melanina) e identificação do recesso pineal.

h) Não foram observadas concreções calcáreas (areia cerebral ou acervulli) em todas as glândulas pineais analisadas macro, e microscopicamente.

\section{Referências}

ADAM, W. S.; CALHOUN, M. L.; SMITH, E. M.; SINSON, A. W. Microscopic anatomy of the dog: a photographic atlas. Springfield: Charles C. Tomas, 1970.

ALTSCHULE, M. D.: Frontiers of pineal physiology. Cambridge, Mass-London: MIT Press, 1975.

ANDERSON, W. D. Atlas of canine anatomy. Malvern: Lea \& Fiebiger, 1994.

BANKS, W. J. Applied veterinary histology. $2^{\text {nd }}$ ed. Baltimore: Williams \& Wilkins, 1986.

BARGMANN, W. Die epiphysis cerebri. In: VON MÖLLENDORFF, W. Handbuchder mikroskopischen anatomie des menschen. Berlin: Springer Verlag, 1943. p.309-505.

BINKLEY, S. The pineal: endocrine and nonendocrine function. Englewood Cliffs: Prentice Hall, 1988.

BLIN, P. C.; MAURIN, C. Anatomie macroscopique de l'epiphyse des mammifères domestiques. Recueil de Medecine Véterinaire, Paris, n.132, p.36-52, 1956. 
CALVO, J.; BOYA, J.; GARCIA-MAURIÑ, J. E.; LOPESCARBONELL, A. Structure and ultrastructure of the pigmented cells in the adult dog pineal gland. Journal of Anatomy, London, v.160, p.67-73, 1988.

DYCE, K. M.; SACK, W. O.; WENSING, C. J. G. Textbook of veterinary anatomy. $2^{\text {nd }}$ ed. Philadelphia: W. B. Saunders Company, 1987.

ELLSWORTH, A. F.; YANG, T-J.; ELSSWORTH, M. L. The pineal body of the dog. Acta Anatomica, Basel, n.122, p.197-200, 1985.

ERHART, E. A. Neuroanatomia. 4.ed. São Paulo: Atheneu, 1968.

HULLINGER, D. L. The endocrine system. In: EVANS, H. E. Evans-Miller's anatomy of the dog. $3^{\text {th }}$ ed. Philadelphia: W. B. Saunders Company, 1993. p. 559-585.

JUNQUEIRA, L. C.; CARNEIRO, J. Histologia básica. Rio de Janeiro: Guanabara Koogan, 1999.

KAPPERS, J. A.: Survey of the innervation of the epiphysis cerebri and the accessory pineal organs of vertebrates. Progress in brain research. n. 10, p. 87-153 (1965)

KAPPERS, A.; HUBER, C.; CROSBY, E. C. The comparative anatomy of the nervous system of vertebrates, including man. New York: Hafner Publishing Company, 1960. v.2,p.1100-1101.

KITAY, J. I.; ALTSCHULE, M. D.: The pineal gland - a review of the physiologic literature. Cambrige: Harvard University Press, 1954.

LERNER, A. B. The pineal. In: WILLIAMS, R. H. Textbook of endocrinology. 3.ed. Philadelphia: W. B. Saunders Company, 1962. p.880.
LERNER, A. B.; CASE, J. S.; TAKAHASHI, Y.; LEE, T. H.; MORI, W. Isolation of $s$ melatonin, the pineal gland factor that lightens melanocytes. Journal of American Chemical Society, Easton, n.80, p.2587, 1958.

MACHADO, A. B. M. Estrutura e funções do subtálamo e do epitálamo. In: MACHADO, A. B. M. Neuroanatomia funcional.2.ed. São Paulo: Atheneu, 1993. p.238.

OKSCHE, A.: Survey of the development and comparative morphology of the pineal organ. Progress in brain research. n. 10, p. $3-29,1965$.

REITER, J. R. The mammalian pineal gland: estructure and function. The American Journal of Anatomy, Philadelphia, n.162, p.287-313, 1981.

SCHAFFER, E. A.; SYMINGTON, J.; BRYCE, T. H. Quains' elements of anatomy. New York: Logmans \& Green, 1909.

TILDEN, A. R.; HUTCHINSON, V. H. Influenceof photoperiod and temperature on serum melatonim in the Diamondback Water Snake (Nerodia rhombifera). General and Comparative Endocrinology, Oklahoma, v.92, n.3, p.347-354, 1993.

VENZKE, W. G.; GILMORE, J. W.: Histological observation on the epiphysis cerebri and the choroid plexus of the third ventricle of the dog. Procedings in Iowa Academy Science. v. 47, p. 409-413,1940.

VENZKE, W. G. Endocrinologia do carnívoro. In: SISSON, S.; GROSSMAN, J. D. Anatomia dos animais domésticos. 5.ed. Rio de Janeiro: Guanabara Koogan, 1986. v.2, p.1496.

VOLLRATH,L. The pineal organ. Berlin: Springer-Verlag, 1981.

ZACH, B.: Topographie und mikroskopisch-anatomischer Feinbau der Epiphysis cerebri von Hund und Katzer. Ventralblatt Für Veterinärmedizin. n.7, p.273 - 303, 1960. 